\title{
SEDANTER ORTA YAŞ BAYANLAR İLE GENÇ BAYANLARDA AEROBİK EGZERSIZIN VÜCUT KOMPOZISYONU VE KAN LIPIDLERINE ETKISI
}

\author{
Selma KARACAN ${ }^{1} \quad$ F.Filiz ÇOLAKOĞLU ${ }^{1}$
}

Geliş Tarihi: 05.11 .2003

Kabul Tarihi: 31.12.2003

\section{ÖZET}

Bu çalışma, sedanter orta yaş ve genç bayanlara 12 haftalık aerobik antrenman programı (koş-yürü) uygulamasının vücut kompozisyonu ve kan lipidlerine etkisini belirlemek amacıyla yapılmıştır.

Gruplar düzenli olarak egzersiz yapmamış, özel bir diyet programı uygulamayan, egzersiz yapmasına engel olacak düzeyde sağlık problemleri olmayan bayanlardan oluşturulmuştur. Her iki gruba da 12 hafta süre ile haftada 3 gün 30 dakikalık koş- yürü egzersiz programı uygulatılmıştır. Antrenman şiddeti Karvonen metoduna göre $\% 70$ olarak belirlenmiş, antrenman öncesi ve antrenman sonrası vücut ağırlığı, vücut yağ yüzdesi, yağsız vücut ağırığı, vücut yağ ağırlığı, vücut kitle indeksi, total kolesterol, LDL kolesterol, HDL kolesterol ve trigliserit değerlerinin ölçümleri yapılmıştır.

Orta yaş bayanların $(n=49)$ yaş ve boy ortalamaları $40,53 \pm 2,93$ yıl, $156,79 \pm 4,20 \mathrm{~cm}$, genç bayanların $(n=23)$ yaş ve boy ortalamaları $26,17 \pm 3,53$ yıl, $160,13 \pm 6,71 \mathrm{~cm}$ olarak belirlenmiştir. Çalışma sonunda, her iki grubunda vücut ağırlı̆ı, vücut yağ yüzdesi, vücut yağ ağırlığı, yağsız vücut ağırlığı, vücut kitle indeksi, total kolesterol ve LDL kolesterol değerlerinde anlamlı bir azalma tespit edilmiştir $(p<.05)$. Ayrıca orta yaş kadınların HDL kolesterol değerlerinde bir artış, trigliserit değerlerinde ise bir azalma belirlenmiş olup, istatistiksel açıdan anlamlılık düzeyinde değildir $(p>.05)$. Sonuç olarak, orta yaş bayanlar ile genç bayanlarda 12 haftalık aerobik egzersizin vücut kompozisyonunda benzer olumlu değişikliklere neden olduğu, kan lipidlerinde ise daha çok orta yaş kadınlar lehine pozitif değişikliklerin olduğu gözlenmiştir.

Anahtar Kelimeler: Bayanlar, Sedanter, Vücut Kompozisyonu, Kan Lipidleri, Egzersiz.

\section{THE EFFECTS OF AEROBIC EXERCISE ON THE BODY COMPOSITION AND BLOOD LIPIDS IN MIDDLE AGED AND YOUNG WOMEN}

\begin{abstract}
The purpose of this study was to determine the effects of 12 weeks aerobic (jog-walk) exercise program on body composition and blood lipids of sedentary middle aged women and young women.

The groups were composed of the women who had not done exercise regularly, who had not followed a special diet and who did not have any health problems preventing them doing any kind of exercise. During 12 weeks, both groups participated in a jog-walk exercise program with the duration of $30 \mathrm{~min}$. and 3 times per week. The intensity of the exercise was $\% 70$ that was determined by Karvonen method. Before and after the training measurements of body weight, body fat \%, body fat weight, lean body mass, body mass index, total cholesterol, LDL cholesterol, HDL cholesterol and of triglyceride were done.

Mean age and height weight of groups were determined as 40,53 $\pm 2,93$ years and $156,79 \pm 4,20 \mathrm{~cm}$. for middle aged group $(n=49)$ and $26,17 \pm 3,53$ years and $160,13 \pm 6,71 \mathrm{~cm}$ for young women $(n=23)$. The results indicated that, although there was a significant decrease in body weight, body fat \%, body fat weight, body mass index, total cholesterol, LDL-C, values ( $p<.05$ ), only in middle aged group there was an increase in HDL-K scores and decrease triglyceride values but not significant ( $p>.05)$.

Consequently, moderate aerobic exercise programs that were done long time and properly had positive effects on body composition in young and middle aged women. As for the blood lipids, such programs had positive effects in favor of mostly middle aged women.

Keywords: Women, Sedentary, Body Composition, Blood Lipids, Exercise.
\end{abstract}

\section{GiRiş}

Günümüzde, hareket azlığı bir hastalık olarak nitelendirilmekte ve birçok ölümcül hastalıkların sebebi olarak gösterilmektedir. Kalp-Damar hastalıkları bu grubun başını çekmektedir. Elbetteki teknolojinin gelişmesiyle, iş kolaylaştıran aletlerin günlük hayatın vazgeçilmez bir parçası olmasının bedensel hareketsizliğe etkisi büyüktür. Sedanter bir yaşam tarzı ise birçok ciddi sağlık problemlerine neden olmaktadır. Çağın hastalığı olarak nitelendirilen obezite ve kardiyovasküler hastalıklar başta olmak üzere kassal zayıflık, postürel bozukluk, diabet gibi birçok hastalıklar hareketsiz ve sedanter bireylerde daha sık görülmektedir $(1,2,3)$.

${ }^{1}$ Gazi Üniversitesi Beden Eğitimi ve Spor Yüksekokulu 
Plazma kolesterol düzeyleri ile koroner kalp hastalığı riski arasında, diğer risk faktörlerinden bağımsız güçlü bir ilişki vardır. LDL kolesterol düzeylerinin yüksek olmasının aterosklerotik kalp hastalığına neden olduğu genetik, deneysel, epidemiyolojik ve klinik çalışmalarla kanıtlanmıştır (4).

Yapılan çalışmalarda total kolesteroldeki \%1'lik artışın koroner kalp hastalığında \%2 artışa, \%1'lik azalmanın ise kalp krizi riskinde \%2-3 oranında azalmaya neden olduğu belirtilmekte, LDL kolesteroldeki \%11'lik azalmanın koroner arter kalp hastalığında \%19 azalmaya, HDL kolesterolde $1 \mathrm{mg} / \mathrm{dl}$ 'lik artışın ise koroner riskte \%3 oranında azalmaya sebep olduğu tespit edilmiştir (5)'.

Vücut ağırlığının normal sınırlar içerisinde tutulması alınan ve harcanan kalorinin eşit olmasına bağlıdır. Günümüzde mekanize olmuş toplumsal yaşam, hareketi azaltarak harcanması gereken enerjiyi vücutta saklı tutmakta ve bu birikim dengeyi olumsuz yönde bozmaktadır (6). Özellikle gelişmiş ülkelerde obezite başlı başına bir sağlık problemi olarak değerlendirilmekte ve alternetif çözüm yolları üretilmeye çalışılmaktadır. Vücut ağırlığının ideal seviyeye ulaşması durumunda koroner arter kalp hastalıkları riskinin \%35-55 oranında azalabileceği belirtilmektedir $(7,8)$.

Bu çalışmada, sedanter orta yaş bayanlar ile genç bayanlara uygulanan 12 haftalık aerobik (koş-yürü) antrenman programının vücut kompozisyonu ve kan lipidlerine etkileri incelenmiştir.

\section{MATERYAL VE METOD}

\section{Araştırmaya Katılan Gruplar ve Özellikleri}

12 haftalık aerobik antrenman programının orta yaş bayanlar ile genç sedanter bayanların vücut kompozisyonu ve kan lipidleri üzerindeki etkilerini belirlemek amacıyla yapılan bu araştırma toplam 72 sağlıklı - gönüllü, deneklerin katılımı ile gerçekleştirilmiştir. Orta yaş bayanların $(n=49)$ yaş ve boy ortalamaları 40,53 $\pm 2,93$ yıl, 156,79 $\pm 4,20$ $\mathrm{cm}$, genç bayanların $(\mathrm{n}=23)$ yaş ve boy ortalamaları $26,17 \pm 3,53$ yıl, 160,13 $\pm 6,71 \mathrm{~cm}$ olarak tespit edildi. Deneklerden egzersiz yapmalarında herhangi bir sakınca olmadığına dair doktor raporu istenmiştir. Ayrıca, deneklerin sağlık hikayelerini öğrenebilmek için anket uygulanmıştır. Deneklere diyet programı verilmemiş, normal diyetlerine devam etmeleri istenmiştir.

\section{Uygulanan Antrenman Programı}

Deneklere hedef kalp atım sayılarının \%70 şiddetinde, 12 hafta, haftada 3 gün , 30 dk arasında koş-yürü egzersizi yaptırıldı. Deneklere antrenman başlamadan 5-10 dk ısınma egzersizi, antrenman sonunda 5-10 dk germe egzersizi yaptırıldı. Egzersizin şiddeti, kalp atım sayısı rezerv (Karvonen) metoduna göre hedef kalp atım sayısı tespit edilmiştir (9).

\section{Araştırmada Uygulanan Ölçümler ve Testler}

Deneklerin vücut kompozisyonu ile ilgili ölçümler Gazi Üniversitesi Beden Eğitimi ve Spor Yüksekokulunun fizyoloji laboratuarında, kan lipid testleri Gazi Üniversitesi Sağlık Kültür ve Spor Dairesi Başkanlığı biyokimya laboratuarlarında yapılmıştır. Deneklere uygulanan tüm ölçümler ve testler antrenman programından bir hafta önce ve antrenman programı bittikten bir hafta sonra olmak üzere iki kez yapıldı.

\section{Boy ve Vücut Ağırlığının Ölçülmesi}

Deneklerin vücut ağırlıkları $0.01 \mathrm{~kg}$ hassasiyeti olan kantarda kilogram cinsinden çıplak ayak, tişört ve tayt ile tartılmıştır. Boyları ise; kantarda sabit olan $0.01 \mathrm{~cm}$ hassasiyetinde metal bir metre ile denekler dik pozisyonda çıplak ayaklı ölçülmüştür.

\section{Vücut Kompozisyonunun Ölçülmesi}

Deneklerin vücut yağ yüzdelerinin belirlenmesinde Cilifton N.J marka skinfold kaliper kullanılmıştır. Vücut yağ yüzdesi triceps ve subrailiac'tan alınan deri kıvrım değerlerinin Sloan ve Weir'in formülü kullanılarak belirlenmiştir (10).

Yağ \%=(4.57/yoğunluk - 4.142) x 100

Yağ Ağırlığı= Vücut Ağırlığı x Yağ \% / 100

Yağsız Vücut Ağırlığı= Vücut Ağırlığı -Yağ Ağırlığı

Vücut Kitle İndeksi= $\mathrm{kg} / \mathrm{m}^{2}$

\section{Kan Lipidlerinin Ölçümü}

Kan Testleri, Gazi Üniversitesi Sağlık Kültür ve Spor Daire Başkanlığı'nın Biokimya laboratuarında uzman kişiler tarafından yapılmıştır. Deneklerin Total kolesterol, HDL-kolesterol, LDL-kolesterol, trigliserit değerleri için ortalama 7cc kan örneği alınmış ve Artax Menarin marka cihazla analiz yapılmıştır.

\section{İstatistiksel Analiz}

Ölçümler sonucu elde edilen veriler her ölçüm sonrası anında kaydedilmiştir. Tüm verilerin aritmetik ortalamaları, standart sapmaları (standart hataları) hesaplanmıştır. Deneklerin ön ve son test değerlerinin karşılaştırılmaları Paired Samples $\mathrm{t}$ - testi ile yapılmış, gruplar arası karşılaştırmalarda ise Independent Sample $\mathrm{t}$ - testi kullanılmıştır. Sonuçların 0.05 önem seviyesinde olup olmadığına bakıımıştır. 
KARACAN, S., ÇOLAKOĞLU, F.F., "Sedanter Orta Yaş Bayanlar İle Genç Bayanlarda Aerobik Egzersizin Vücut Kompozisyonu ve Kan Lipidlerine Etkisi"

\section{BULGULAR}

Tablo 1: Orta Yaş Bayanlar ile Genç Bayanların Antrenman Öncesi ve Antrenman Sonrası Vücut Kompozisyon ve Kan Lipid Değerlerinin Karşılaştırılması

\begin{tabular}{|c|c|c|c|c|c|c|c|c|}
\hline \multirow[b]{2}{*}{ Değişkenler } & \multicolumn{4}{|c|}{ Orta Yaş Bayanlar } & \multicolumn{4}{|c|}{ Genç Bayanlar } \\
\hline & $\begin{array}{c}\text { Ant. } \\
\text { Önc. } \\
\text { N =49 }\end{array}$ & $\begin{array}{l}\text { Ant. } \\
\text { Son. } \\
n=49\end{array}$ & $\begin{array}{l}\text { \%'lik } \\
\text { değ. }\end{array}$ & $\mathbf{t}$ & $\begin{array}{l}\text { Ant. } \\
\text { Önc. } \\
n=23\end{array}$ & $\begin{array}{l}\text { Ant. } \\
\text { Son. } \\
n=23\end{array}$ & $\begin{array}{l}\text { \%'lik } \\
\text { değ. }\end{array}$ & $\mathbf{t}$ \\
\hline $\begin{array}{l}\text { Vücut Ağırlığı } \\
(\mathrm{kg})\end{array}$ & $\begin{array}{c}81,57 \\
\pm 11,20\end{array}$ & $\begin{array}{c}76,29 \\
\pm 10,40\end{array}$ & 6,47 & $16,39^{*}$ & $\begin{array}{c}68,26 \\
\pm 11,72\end{array}$ & $\begin{array}{c}64,69 \\
\pm 10,65\end{array}$ & 5,23 & $11,86^{*}$ \\
\hline $\begin{array}{c}\text { Vücut Yağ } \\
\text { Yüzdesi (\%) }\end{array}$ & $\begin{array}{l}29,16 \\
\pm 4,85\end{array}$ & $\begin{array}{l}25,78 \\
\pm 4,14\end{array}$ & 11,59 & $14,67^{*}$ & $\begin{array}{l}23,55 \\
\pm 5,07\end{array}$ & $\begin{array}{l}20,99 \\
\pm 3,97\end{array}$ & 10,87 & $5,30^{*}$ \\
\hline $\begin{array}{c}\text { Vücut Yağ } \\
\text { Ağırığı (kg) }\end{array}$ & $\begin{array}{l}24,31 \\
\pm 6,64\end{array}$ & $\begin{array}{l}19,95 \\
\pm 5,24\end{array}$ & 17,93 & $14,20^{*}$ & $\begin{array}{l}16,54 \\
\pm 6,15\end{array}$ & $\begin{array}{l}13,92 \\
\pm 4,82\end{array}$ & 15,84 & $5,72^{*}$ \\
\hline $\begin{array}{l}\text { Yağsız Vücut } \\
\text { Ağırlığı (kg) }\end{array}$ & $\begin{array}{l}57,33 \\
\pm 5,83\end{array}$ & $\begin{array}{l}56,39 \\
\pm 6,22\end{array}$ & 1,63 & $3,32^{*}$ & $\begin{array}{l}51,71 \\
\pm 6,17\end{array}$ & $\begin{array}{l}50,77 \\
\pm 6,18\end{array}$ & 1,81 & $3,06^{*}$ \\
\hline $\begin{array}{l}\text { Vücut Kitle } \\
\text { İnd. }\left(\mathrm{kg} / \mathrm{m}^{2}\right)\end{array}$ & $\begin{array}{l}33,31 \\
\pm 5,09\end{array}$ & $\begin{array}{l}31,01 \\
\pm 4,67\end{array}$ & 6,90 & $13,52^{*}$ & $\begin{array}{l}26,81 \\
\pm 5,38\end{array}$ & $\begin{array}{l}25,40 \\
\pm 4,89\end{array}$ & 5,25 & $11,16^{*}$ \\
\hline $\begin{array}{l}\text { T. Kolesterol } \\
(\mathrm{mg} / \mathrm{dl})\end{array}$ & $\begin{array}{r}191,48 \\
\pm 37,78\end{array}$ & $\begin{array}{l}179,24 \\
\pm 32,02\end{array}$ & 6,39 & $3,23^{*}$ & $\begin{array}{l}186,04 \\
\pm 44,00\end{array}$ & $\begin{array}{r}163,95 \\
\pm 35,99\end{array}$ & 11,87 & $4,25^{\star}$ \\
\hline $\begin{array}{l}\mathrm{HDL}-\mathrm{K} \\
\text { (mg/dl) }\end{array}$ & $\begin{array}{l}37,55 \\
\pm 9,95\end{array}$ & $\begin{array}{c}39,41 \\
\pm 11,27\end{array}$ & 4,95 & 1,57 & $\begin{array}{l}39,47 \\
\pm 7,63\end{array}$ & $\begin{array}{l}39,03 \\
\pm 8,60\end{array}$ & 1,11 & ,233 \\
\hline $\begin{array}{l}\text { LDL-K } \\
(\mathrm{mg} / \mathrm{dl})\end{array}$ & $\begin{array}{r}151,91 \\
\pm 41,22\end{array}$ & $\begin{array}{r}136,60 \\
\pm 36,25\end{array}$ & 10,07 & $4,15^{*}$ & $\begin{array}{r}146,56 \\
\pm 45,37\end{array}$ & $\begin{array}{r}124,92 \\
\pm 37,34\end{array}$ & 14,76 & $3,97^{*}$ \\
\hline $\begin{array}{l}\text { Triliserid } \\
\text { (mg/dl) }\end{array}$ & $\begin{array}{r}125,77 \\
\pm 70,35\end{array}$ & $\begin{array}{l}115,62 \\
\pm 54,31\end{array}$ & 8,07 & 1,51 & $\begin{array}{c}98,81 \\
\pm 40,53\end{array}$ & $\begin{array}{c}98,73 \\
\pm 34,34\end{array}$ & 0,08 & ,019 \\
\hline
\end{tabular}

${ }^{*} \mathrm{p}<0,05$

Tablo 1 incelendiğinde, genç bayanlar ile orta yaş bayanların vücut ağırlığı, vücut yağ yüzdesi, vücut yağ ağırlığı, yağsız vücut ağırlığı, vücut kitle indeksi, total-K, LDL-K, değerlerinde anlamlı bir azalma tespit edilmiştir $(p<0,05)$.

Tablo 2: Grupların Antrenman Öncesi ve Antrenman Sonrası Vücut Kompozisyon ve Kan Lipid Değerlerinin Karşılaştırılması

\begin{tabular}{|c|c|c|c|c|c|c|c|c|}
\hline & \multicolumn{4}{|c|}{ Ant. Önc. } & \multicolumn{4}{|c|}{ Ant. Son. } \\
\hline Değişkenler & $\begin{array}{c}\text { Orta } \\
\text { Yaş } \\
n=49\end{array}$ & $\begin{array}{c}\text { Genç } \\
\text { Yaş } \\
n=23\end{array}$ & $\begin{array}{l}\text { \%'lik } \\
\text { değ. }\end{array}$ & $\mathbf{t}$ & $\begin{array}{c}\text { Orta } \\
\text { Yaş } \\
n=49\end{array}$ & $\begin{array}{c}\text { Genç } \\
\text { Yaş } \\
n=23\end{array}$ & $\begin{array}{l}\text { \%'lik } \\
\text { değ. }\end{array}$ & $\mathbf{t}$ \\
\hline $\begin{array}{l}\text { Vücut } \\
\text { Ağırlığı } \\
(\mathrm{kg})\end{array}$ & $\begin{array}{c}81,57 \\
\pm 11,20\end{array}$ & $\begin{array}{c}68,26 \\
\pm 11,72\end{array}$ & 16,31 & $4,55^{\star}$ & $\begin{array}{c}76,29 \\
\pm 10,40\end{array}$ & $\begin{array}{r}64,69 \\
\pm 10,65\end{array}$ & 15,20 & $4,34^{*}$ \\
\hline $\begin{array}{l}\text { Vücut Yağ } \\
\text { Yüzdesi (\%) }\end{array}$ & $\begin{array}{l}29,16 \\
\pm 4,85\end{array}$ & $\begin{array}{l}23,55 \\
\pm 5,07\end{array}$ & 19,23 & $4,44^{*}$ & $\begin{array}{l}25,78 \\
\pm 4,14\end{array}$ & $\begin{array}{l}20,99 \\
\pm 3,97 \\
\end{array}$ & 18,58 & $4,63^{*}$ \\
\hline $\begin{array}{l}\text { Vücut Yağ } \\
\text { Ağırlığı (kg) }\end{array}$ & $\begin{array}{l}24,31 \\
\pm 6,64 \\
\end{array}$ & $\begin{array}{r}16,54 \\
\pm 6,15 \\
\end{array}$ & 31,96 & $4,73^{*}$ & $\begin{array}{l}19,95 \\
\pm 5,24 \\
\end{array}$ & $\begin{array}{l}13,92 \\
\pm 4,82 \\
\end{array}$ & 30,22 & $4,65^{*}$ \\
\hline $\begin{array}{l}\text { Yağsız Vücut } \\
\text { Ağırlığı (kg) }\end{array}$ & $\begin{array}{r}57,33 \\
\pm 5,83\end{array}$ & $\begin{array}{l}51,71 \\
\pm 6,17\end{array}$ & 9,80 & $3,73^{*}$ & $\begin{array}{l}56,39 \\
\pm 6,22\end{array}$ & $\begin{array}{l}50,77 \\
\pm 6,18\end{array}$ & 9,96 & $3,58^{*}$ \\
\hline $\begin{array}{l}\text { Vücut Kitle } \\
\text { İnd. }\left(\mathrm{kg} / \mathrm{m}^{2}\right)\end{array}$ & $\begin{array}{l}33,31 \\
\pm 5,09\end{array}$ & $\begin{array}{l}26,81 \\
\pm 5,38\end{array}$ & 19,51 & $4,96^{*}$ & $\begin{array}{l}31,01 \\
\pm 4,67\end{array}$ & $\begin{array}{l}25,40 \\
\pm 4,89\end{array}$ & 18,09 & $4,60^{*}$ \\
\hline $\begin{array}{l}\text { T.Kolesterol } \\
(\mathrm{mg} / \mathrm{dl})\end{array}$ & $\begin{array}{r}191,48 \\
\pm 37,78 \\
\end{array}$ & $\begin{array}{l}186,04 \\
\pm 44,00 \\
\end{array}$ & 2,84 &, 541 & $\begin{array}{l}179,24 \\
\pm 32,02 \\
\end{array}$ & $\begin{array}{r}163,95 \\
\pm 35,99 \\
\end{array}$ & 8,53 & 1,73 \\
\hline $\begin{array}{l}\text { HDL-K } \\
\text { (mg/dl) }\end{array}$ & $\begin{array}{l}37,55 \\
\pm 9,95\end{array}$ & $\begin{array}{l}39,47 \\
\pm 7,63\end{array}$ & 5,11 & ,871 & $\begin{array}{c}39,41 \\
\pm 11,27\end{array}$ & $\begin{array}{l}39,03 \\
\pm 8,60\end{array}$ & 0,96 & ,144 \\
\hline $\begin{array}{l}\text { LDL-K } \\
\text { (mg/dl) }\end{array}$ & $\begin{array}{l}151,91 \\
\pm 41,22\end{array}$ & $\begin{array}{l}146,56 \\
\pm 45,37\end{array}$ & 3,52 & ,497 & $\begin{array}{l}136,60 \\
\pm 36,25\end{array}$ & $\begin{array}{l}124,92 \\
\pm 37,34\end{array}$ & 8,55 & 1,249 \\
\hline $\begin{array}{l}\text { Trigliserid } \\
(\mathrm{mg} / \mathrm{dl})\end{array}$ & $\begin{array}{l}125,77 \\
\pm 70,35\end{array}$ & $\begin{array}{c}98,81 \\
\pm 40,53\end{array}$ & 21,43 & 1,705 & $\begin{array}{l}115,62 \\
\pm 54,31\end{array}$ & $\begin{array}{c}98,73 \\
\pm 34,34\end{array}$ & 14,60 & 1,366 \\
\hline
\end{tabular}

Tablo 2'ye bakıldığında, genç bayanlar ile orta yaş bayanların antrenman öncesi ve antrenman sonrası total kolesterol, LDL kolesterol, HDL kolesterol ve trigliserid değerlerinde anlamlı bir fark tespit edilemezken $(p>0,05)$, orta yaş bayanların antrenman öncesi ve antrenman sonrası vücut ağırlığı, vücut yağ yüzdesi, vücut yağ ağırlığı, yağsız vücut ağırlığı ve vücut kitle indeksi genç bayanlara göre anlamlı derecede yüksek bulunmuştur $(p<0,05)$. 


\section{TARTIŞMA VE SONUÇ}

Bu çalışmada, orta yaş bayanlar ile genç sedanter bayanlara 12 haftalık aerobik (koş-yürü) egzersiz yaptırılarak, egzersiz öncesi ve sonrası vücut kompozisyonu ve kan lipidlerindeki değişiklikler incelenmiştir.

Carol ve arkadaşları, yaşları 24-48 arasında olan 60 erkek ve bayana 8 hafta süre ile aerobik dans ve koş-yürü egzersizi uygulamışlar ve çalışma sonunda iki grubunda vücut ağırlığında anlamlı bir farklılık bulamamışlardır (11).

Saçaklı ve arkadaşları yaş ortalamaları 35,2 $\pm 5,2$ yıl olan 16 obez bayana 1 ay süre ile kalp atım sayılarının \%60-70 şiddetinde bisiklet egzersizi, genel, özel cimnastik ve maksimal kuvvetlerinin \%20-40'ı ile ağırlık çalışması yaptırmışlar, egzersiz öncesi deneklerin vücut yağ yüzdesi 37,8 iken egzersiz sonrası 33,27'ye düştüğünü belirtmişlerdir (12).

Nindl ve arkadaşları (2000) 31 sağlıklı bayana 6 ay süre ile haftada 5 gün rezistans ve aerobik kombinasyonundan oluşan bir egzersiz programı uygulamışlar antrenman öncesi ve sonrası vücut ağırlık ortalamalarını $66,5-64,8 \mathrm{~kg}$, yağ ağırlık ortalamalarını 24,7-22,1 kg, yağsız vücut ağırlığını 41,8-42,7 kg olarak tespit etmişler, antrenman sonunda vücut ağırlığında\%2,2 yağ ağırlığında \%10 oranında bir azalma yağsız vücut ağırlığında ise \%2,2 oranında bir artış kaydetmişlerdir (13).

Suzuki, Yamada ve Sugiura (1998) yaşları 20-62 yılları arasında olan 118'i bayan toplam 220 deneğin fiziksel aktivite düzeyleri ve kardiyovasküler fitneslerini belirleyerek koroner arter risk faktörleri ile ilişkisini incelemişlerdir. Deneklerin kardiyovasküler fitneslerini prograsif submaksimal bisiklet ergometresi ile bir haftalık fiziksel aktivite düzeylerini ise deneklerin bellerine taktıkları accelerometre ile tespit etmişlerdir. Kardiyovasküler fitnes ve fiziksel aktivite seviyeleri düşük olan bayanların vücut kitle indeksleri ile vücut yağ yüzdelerini orta fakat yüksek fitnes ve fiziksel aktivite düzeylerine sahip olanlara göre anlamlı derecede yüksek bulmuşlardır (14).

Amano, Kanda ve Maritani (2001), 18 obez deneğe 3 ay süreyle haftada 3 gün 30 dakikalık aerobik egzersiz uygulatmışlar, antrenman öncesi ve sonrası vücut ağırlık ortalamalarını 74,1 $\pm 2,6-70,3 \pm 2,9$ kg., vücut kitle indeks ortalamalarını $27,3 \pm 0,4-25,9 \pm 0,5 \mathrm{~kg} / \mathrm{m}^{2}$, vücut yağ yüzde ortalamalarını $29,6 \pm 1,3-26,6 \pm 1,3 \%$, vücut yağ ağırlık ortalamalarını $21,7 \pm 0,9-18,6 \pm 1$, yağsız vücut kitlesi ortalamalarını $52,4 \pm 2,5-51,7 \pm 2,6 \mathrm{~kg}$ olarak tespit etmişler ve yağsız vücut kitlesi dışındaki diğer değişkenlerin arasındaki farkın anlamlı olduğunu belirtmişlerdir (15).

Lorei, Ballard, Mckeown ve Zinkgraft (1990), yaşları 35-70 yılları arasında olan menopoz dönemine girmemiş $(n=43)$ ve menopoz dönemindeki $(n=66)$ toplam 109 bayana 6 ay süre ile haftada 3 gün her seans 60 dakika olacak şekilde yürüme-jog ve hafif ağırlık egzersizleri yaptırarak vücut kompozisyonundaki değişiklikleri incelemişlerdir. Egzersiz sonrasında menopoz dönemine girmemiş bayanlar ile menopoz dönemindeki bayanların vücut kompozisyonlarının egzersize cevabının benzer olduğunu ve egzersiz grubunun yağ oranlarının sedanter gruba göre daha düşük olduğunu tespit etmişlerdir (16).

Szmedra ve arkadaşları (1998), genç bayanlara 6 haftalık koşu bandı egzersizi uygulamışlar ve vücut kompozisyonundaki değişiklikleri incelemişlerdir. Deneklerin vücut yağ yüzdesi antrenman öncesi $33 \pm 4$ antrenman sonrası $31,7 \pm 3,9$ olarak tespit etmişler ve çalışma sonunda vücut yağ yüzdelerinde \%1,3'lük bir azalma olduğunu belirtmişlerdir (17).

Obez genç erkek ve bayanlarda 16 aylık orta şidetteki egzersizin vücut ağırlığı ve kompozisyonuna etkileri araştırılmış ve egzersiz sonunda kontrol grubunun deney grubuna göre vücut ağırlığı $2.9 \pm 5,5 \mathrm{~kg}$, vücut kitle indeksi $1,1 \pm 2$ $\mathrm{kg} / \mathrm{m}^{2}$ ve yağ kitlesi $2.1 \pm 4,8 \mathrm{~kg}$ daha fazla tespit edilmiştir. Sonuç olarak uzun süreli orta şiddete yapılan egzersizlerin vücut ağırlığının azaltılmasında etkili olduğu belirtilmiştir (18).

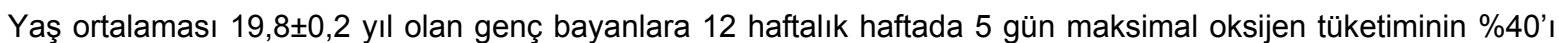
şiddetinde bisiklet ergometresinde egzersiz uygulatılmış ve egzersiz sonunda vücut kitle indeksi, yağ kitlesi, vücut ağırığı ve skinfold deri kıvrım kalınlıklarında anlamlı bir azalma kaydedilmiştir (19).

Çalışmamızda 12 haftalık aerobik egzersizin her iki grupta da vücut ağırlığını, yağ yüzdesini, vücut kitle indeksini, yağ ağırlığını, yağsız vücut ağırığını anlamlı derecede düşürdüğü tespit edilmiştir $(p<0.05)$.

Deneklerden egzersiz süresince günlük yeme alışkanlıklarına devam etmeleri istenmesine rağmen fazla kilolarından şikayetçi olan bayanların grup içerisinde daha fazla kilo verebilmek amacıyla diyet yapmış olabilecekleri düşünülmektedir. Deneklerin yağsız vücut ağırlıklarındaki azalma egzersizle birlikte diyet yapmalarından kaynaklanmış olabilir. Bu konu ile ilgili yapılan pek çok çalışmada aerobik egzersiz ile diyet kısıtlamasının birlikte uygulandığı programların vücut ağırlığını, yağ yüzdesini ve yağsız vücut ağırlığını anlamlı derecede azalttığı belirtimekte ve yağsız vücut ağırlığındaki bu azalmanın kas kaybı ve vücuttaki protein miktarının azalmasından kaynaklanabileceği bildirilmektedir $(20,21,22,23)$.

Kilo azaltıcı programlar kadınlarda koroner arter kalp hastalık riskini azaltmaktadır. Sedanter bir yaşam ise vücut ağırığının aşırı artmasıyla oluşan obezite hastalığının en önde gelen sebeplerinden birisidir. Pek çok araştırma, uzun süre düzenli olarak orta şiddette aerobik nitelikte yapılan egzersizlerin vücut ağırlığını, vücut yağ yüzdesini, vücut kitle indeksini azalttığını bildirmektedir $(24,25)$.

$\mathrm{Bu}$ çalışmada, orta yaş bayanlar ile genç bayanların antrenman sonrası total kolesterol ve LDL kolesterol değerlerinde anlamlı bir azalma belirlenirken $(p<.05)$, HDL-K ve trigliserit değerinde anlamlı bir değişiklik tespit edilmemiştir ( $p>.05)$.

Fiziksel aktivitelerin koroner kalp hastalıkları riskini azaltabileceği ve antioksidan-proksidan dengede olumlu değişikliklere neden olabileceği belirtilmektedir. 17 sağlıklı ve sedanter bayan ve erkeğe 16 haftalık aerobik egzersiz 
uygulanmış egzersiz öncesi ve sonrası kan lipidleri incelenmiştir. Sonuç olarak düzenli yapılan fiziksel aktivitelerin LDL oksidasyon direncini arttırdığı, LDL konsantrasyonundaki oksitlenmeyi ise azalttığı belirtilmektedir (26).

Vücut ağırlığı fazla olan 44 hipertansiyonlu yetişkine 9 hafta süre ile düzenli olarak aerobik egzersiz yaptırılmış ve hipertansiyonu azaltmaya yönelik diet uygulanmıştır. Program sonunda deney grubunun vücut ağırlığında $4.9 \mathrm{~kg}$, total kolesterolde $25 \mathrm{mg} / \mathrm{dl}$, LDL kolesterolde $18 \mathrm{mg} / \mathrm{dl}$ ve HDL kolesterolde $5 \mathrm{mg} / \mathrm{dl}$ oranında azalma kaydetmişlerdir (27).

7 sedanter genç bayana 30-60 dakikalık maksimal oksijen tüketiminin \%60'ı şiddetinde egzersiz uygulanmış ve total kolesterol, HDL kolesterol trigliserit ve apolipoproteinlere etkileri araştırılmış. Kan örnekleri egzersize başlamadan önce, egzersiz bitiminden 30 dk., 1-2-24 saat sonra alınmış egzersiz öncesi ve sonrası kan lipidlerinde anlamlı bir farka rastlanamamıştır. Sonuç olarak normal lipid profiline sahip sedanter bayanlarda egzersizin kan lipidlerini değiştirmediği belirtilmiştir (28).

Değişik egzersizlerin lipoprotein ve lipid profiline, kardiyovasküler fitnes ve vücut kompozisyonuna etkilerini belirlemek amacıyla 16 hafta süre ile yaş ortalaması 20,4 yıl olan 48 sedanter bayanın 12'sine aerobik egzersizi, 12'sine rezistans egzersizi, 12'sine aerobik ve rezistans egzersizi uygulanmış 12'side kontrol grubunu oluşturmuştur. Program sonunda yalnızca aerobik egzersiz grubunun vücut yağ yüzdesi ve trigliserid değerleri anlamlı derecede düşük, HDL kolesterol ise anlamlı derecede yüksek bulunmuştur (29).

Yaşları 18-22 yılları arasında olan 12 sedanter bayana 7 haftalık merdiven tırmanma egzersizi uygulatılmış ve egzersiz sonunda bayanların HDL kolesterol konsantrasyonlarında artış olduğu tespit edilmiştir (30).

Yaşları 18-30 yılları arsında olan siyah-beyaz erkek ve kadınların fiziksel fitnes ve fiziksel aktivite düzeyleri ile kan lipidleri arasındaki ilişki araştırılmış ve fiziksel fitnes ve aktivitesi düşük olanların yüksek olanlara göre vücut ağırlıklarının yüksek, HDL kolesterollerinin de düşük olduğu belirtilmiştir (31).

Furukawa, ve arkadaşları (2003) orta yaş bayanlara 12 haftalık bir yürüyüş programı uygulamışlar ve program sonunda deney grubunun HDL kolesterol düzeylerinde $1.8 \pm 8.3 \mathrm{mg} / \mathrm{dl}$ 'lı artış, kontrol grubunda ise $-2.9 \pm 7.0 \mathrm{mg} / \mathrm{dl}$ oranında azalma tespit etmişlerdir (32).

Genç bayanlarla ilgili yapılan başka bir çalışmada ise fiziksel aktivite düzeyi yüksek olanların vücut yağ yüzdesi ve total kolesterol değerlerinin düşük olduğu bildirilmiştir (33).

Yaşları 19-26 yılları arasında olan genç bayanlardan haftada 3-5 gün düzenli olarak aerobik içerikli egzersiz yapanlar ile düzenli olarak egzersiz yapmayanların vücut kitle indeksi, total kolesterol, HDL kolesterol, LDL kolesterol ve trigliserid değerleri arasında anlamlı bir fark bulunamamıştır (34).

Yapılan başka bir çalışmada ise 12 haftalık bir egzersiz sonrasında genç erkeklerin plazma trigliserid, HDL kolesterol, LDL kolesterol ve VLDL kolesterol değerlerinde anlamlı bir farklılık olduğu belirtilirken bayanların lipid düzeylerinde ise anlamlı bir değişikliğe rastlanmamıştır (35).

Ergen ve arkadaşları (2002) yaşları 28-53 arasında olan kilolu bayanlara 12 hafta süreyle iki farklı egzersiz uygulamışlardır. Birinci gruba cimnastik hareketlerini içeren interval egzersiz, ikinci gruba da yürüyüş koşu egzersizi şeklinde 12 hafta boyunca, haftada üç gün ve bir saat süreyle yaptırmışlardır. Antrenman sonunda her iki grupta da HDL kolesterolün LDL kolesterole oranının anlamlı derecede arttığını tespit etmişlerdir (36)

Katzmarzyk ve arkadaşları (2001), yaşları 17-65 yılları arsında olan toplam 650 erkek ve bayan deneklere 20 haftalık aerobik egzersiz uygulayarak aerobik fitnes, kan lipidleri ve vücut yağ kitlesindeki değişiklikleri incelemişlerdir. Antrenman sonunda deneklerin vücut yağ kitlelerinde \%3,3 oranında bir azalma kaydetmişler ve bayanların vücut yağ kitlesindeki değişiklikler ile LDL-K, total kolesterol, total-K/HDL-K lipid değişim indeksleri arasında anlamlı bir ilişki gözlemlemişlerdir (37).

Hareketsiz sedanter bir yaşam tarzı vücut kompozisyonu ve kan lipid profilinde olumsuz değişikliklere neden olmaktadır. Düzenli olarak yapılan egzersizlerin arterioskleroz oluşumunu kolaylaştıran LDL kolesterol düzeyini azattığı, arterioskleroza engel olan HDL kolesterolü ise arttırdığı belirtilmektedir $(38,39)$.

Sonuç olarak 12 hafta süre ile haftada 3 gün hedef kalp atım sayısının \%70'i şiddetinde yapılan koş-yürü egzersizinin kan lipid profilini ve vücut kompozisyonunu olumlu yönde değiştirerek kardiyovasküler sağlığı korumada etkili olabileceği söylenebilir. Özellikle organik çöküntünün hızlandığı orta yaş ve sonraki dönemlerde yaşam kalitesini yükseltmek ve hastalıklardan korunmak için düzenli olarak aerobik egzersizlerin yapılması önerilmektedir.

\section{KAYNAKLAR}

1. Cox, L.C., Burke, V., Morton, A.R., "Long-Term Effects of Exercise on Blood Pressure and Lipids in Healthy Woman Aged 40-65 Years: The Sedentary Women Exercise Adherence Trial (Sweat)", Journal of Hypertension, 19(10), pp. 1733-1743, 2001.

2. Guo, S.S., Zeller, C., Chumlea, W.C., "Aging, Body Composition and Lifestyle: The Fels Longitudinal Study", Am. J. Clin. Nutr., 70(3), pp. 405-411, 1999.

3. Zorba, E., Herkes İçin Spor ve Fiziksel Uygunluk, Neyir Matbaası, Ankara, 1999.

4. Solak, H., Görmüş, I.S., Solak, T., Görmüş, N., Spor ve Kalbimiz, Nobel Yayın Dağıtım, Ankara, 2002.

5. Studd, J., The Management of the Menopause, the Millennium Review, Parthenon Publishing, 2000.

6. Açıkada C., Ergen E., Bilim ve Spor, Tek Ofset Matbaacılık, Ankara, 1990.

7. Rogerio, A., Lobo, M.D., Treatment of the Postmenopausal Women, Basic and Clinical Aspects, New York, 1994.

8. Shangold, M.M., "Exercise in the Menopausal Women", Obstet Gynecol, 75(4), pp. 53-58, 1990.

9. Fox, Bowers, Foss, Beden Eğitimi ve Sporun Fizyolojik Temelleri, Çev: Cerit, M., Bağırgan Yayımevi, Ankara, 1990.

10. Tamer, K., Sporda Fiziksel Fizyolojik Performansın Ölçülmesi ve Değerlendirilmesi, Bağırgan Yayımevi, Ankara, 2000. 
11. Carol, E.G., Julie, S., Mckinney, M.S., Richard, A., Carleton, M.D., "Is Aerobic Dance an Effective Alternative to Walk-Jog Exercise Training" The Journal of Sports Medicine and Physical Fitness, 32(2), pp. 136-141, 1992.

12. Saçaklı, H., Öztürk, M., Saçaklı, M., "Aerobik Egzersiz ve Diyetin Obez Bayanlarda Antropometrik ölçümlere ve Solunum Parametrelerine Etkisi”, Spor Hekimliği Dergisi, 32, pp. 43-53,1997.

13. Nindl, B.C., Harman, E.A., Marx, J.O., Gotshalk, L.A., "Regional Body Composition Changes in Women After 6 Months of Periodized Physical Training", Journal of Applied Physiology, 88(6), pp. 2251-2259, 2000.

14. Suzuki, I., Yamada, H., Sugiura, T., "Cardiovascular Fitness, Physical Activity and Selected Coronary Heart Disease Risk Factors in Adults", The Journal of Sports Medicine and Physical Fitness, 38, pp. 149-157, 1998.

15. Amano, M., Kanda, T., Maritani, T., "Exercise Training and Autonomic Nervous System Activity in Obese Individuals", Medicine Science in Sports Exercise, 33(8), pp. 1287-1291, 2001.

16. Lorei, G.S., Ballard, J.E., Mckeown, B.C., Zinkgraft, S.A., "Body Composition Alterations Consequent to an Exercise Program for Pre and Postmenopausal Women" Journal of Sports Medicine and Physical Fitness, 30(4), pp. 426-433, 1990.

17. Szmedra, L., Lemura, L.M., Shearn, W.M., "Exercise Tolerance, Body Composition and Blood Lipids in Obese African-American Women Following Short-Term Training", The Journal of Sports Medicine and Physical Fitness, 38, pp. 59-65,1998.

18. Donnelly, J.E., Hill, J.O., Jacobson, D.J., Potteigor, J., Sullivan, D.K., Johnson, S.L., Heelan, K., Hise, M., "Effects of a 16 Month Randomized Controlled Exercise Trial on Body Weight and Composition in Young, Overweight Men and Women: The Midwest Exercise Trial", Arch.Intern. Med., 163(11), pp. 1343-1350, 2003.

19. Suzuki, S., Urata, G., Ishida, Y., Kanahisa, H., Yamamura, M. "Influences of Low Intensity Exercise on Body Composition, Food Intake and Aerobic Power of Sedentary Young Females", Appl. Human Sci., 17(6), pp. 259-266, 1998.

20. Glass, J.N., Miller, W.C., Szymanski, L.M., Fernhall, B., Durstire, J.L. "Physiological Responses to Weight-Loss Intervention in Inactive Obese African- American and Caucasian Women”, J. Sport Med. Phys. Fitness, 42(1), pp. 56-64, 2002.

21. Bryner, R.W., Ullrich, I.H., Saueres, J., Donley, D., Hornsby, G., Kolar, M., Yeater, R. "Effects of Resistance and Aerobic Training Combined with an 800 Calorie Liquid Diet on Lean Body Mass and Resting Metabolic Rate", Journal of the American College of Nutrition, 18(2), pp. 115-121, 1999.

22. Donelly, J.E., Pronk, N.P., Jacobsan, D.J., Pronk, S.J., Jakicic, I.M. "Effects of Very-Low Calorie Diet and Physical Training Regimens on Body Composition and Resting Metabolic Rate in Obese Females", Am. J. Clin. Nutr., 54, pp. 56-61, 1991.

23. Froidevanx, F., Schutz, Y., Chritin, L., Jequirer, E. "Energy Expenditure in Obese Women Before and During Weight Loss After Refeeding and in the Weight-Relapse Period", Am. J. Clin. Nutr., 57, pp. 35-42, 1993.

24. Okyar, M., Yaşayan Kalbiniz ve Siz, Timaş Yayınları, İstanbul, 1998.

25. Ponje, G.A.E.P., Janssen, E.M.E., Hermans,J., Mersch, J., "Regular Physical Activity and Changes in Risk Factors For Coronary Heart Disease: A Nine Months Prospective Study", Eur. J. Clin. Chem. Clin. Biochem, 34, pp. 477-483, 1996.

26. Elosua, R., Molina, L., Fito, M., Arquer, A., "Response of Oxidative Stress Biomarkers to a 16 Week Aerobic Physical Activity Program and to Acute Physical Activity in Healthy Young Men and Women”, Atherosclerosis, 167(2), pp.327-334, 2003.

27. Miller, E.R., Erlinger, T.P., Young, D.R., Jehn, M., Charleston, J., Rhodes, D., Wason, S.K., Appel, L.J., "Result of the Diet, Exercise and Weight Loss Intervention Trial (DEW-IT)", Hypertension, 40(5), pp. 612-618, 2002.

28. Imamura, H., Katagiri, S., Uchid, K., Miyamato, N., Nakaro, H., Shirota, T., "Acute Effects of Moderate Exercise on Serum Lipids, Lipoproteins and Apolipoproteins in Sedentary Young Women”, Clin. Exp. Pharmacol Physiol, 27(12), pp. 975-979, 2000.

29. LeMura, L.M., VonDuvillard, S.P., Andreacci, J., Klebez, J.M., Chelland, S.A., Russo, J., "Lipid and Lipoprotein Profiles, Cardiovascular Fitness, Body Composition and Diet During and After Resistance, Aerobic and Combination Training in Young Women", Eur. J. Appl. Physiol, 82(5-6), pp. 451-458, 2000.

30. Boreham, C.A., Wallace, W.F., Nevill, A., "Training Effects of Accumulated Daily Stair-Climbing Exercise in Previously Sedentary Young Women", Prev. Med., 30(4), pp. 277-281, 2000.

31. Sternfeld, B., Sidney, S., Jacobs, D.R., Sadler, M.C., Haskell, W.L., Schreiner, P.J., "Seven Year Changes in Physical Fitness, Physical Activity and Lipids Profile in the Cardial Study. Coronary Artery Risk Developmant in Young Adults", Ann. Epidemiol, 9(1), pp. 25-33, 1999.

32. Furukawa, F., Kazuma, K., Kawa, M., Miyashita, M., Niiro, K., Kusukawa, R., Kojima, M., "Effects of an off-site Walking Program on Energy Expenditure Serum Lipids and Glucose Metabolism in Middle-Aged Women”, Biol. Res. Nurs., 4(3), pp. 181-192, 2003.

33. Lloyd, T., Chinchilli, V.M., Rollings, N., Kieselhorst, K., Tregea, D.F., Henderson, N.A., Sinoway, L.I., " Fruit Consumption, Fitness and Cardiovascular Health in Female Adolescants: The Penn State Young Women's Health Study", Am., J., Clin., Nutr., 67(4), pp. 624-630, 1998.

34. Hata, K., Hata, T., Miyazaki, K., Kunishi, H., Masuda, J., "Effect of Regular Aerobic Exercise on Cerebrovascular Tone in Young Women", Ultrasound. Med., 17(2), pp. 133-136, 1998.

35. Xi, X.R., Qureshi, I.A., Wu, X.D., Khan, I.H., Huang, Y.B., Shiarkar, E., "The Effect of Exercise Training on Physical Fitness and Plasma Lipids in Young Chinese Men And Women”, Zhonghua Yi Xue Za Zhi (Taipei), 59(6), pp. 341-347, 1997.

36. Ergen, N., Sanrı, M., Köseoğlu, S., Arı, Ö., Kırım, S., Sert, M., "Fazla Kilolu Kadınlarda İki Farkıı Egzersiz Modelinin Kilo Verme ve Kan Lipid Profili Üzerine Etkisi”, 7. Uluslararası Spor Bilimleri Kongresi, 27-29 Ekim 2002.

37. Katzmarzyk, P.T., Leon, A.S., Rankinen, T., Gagnon, J., "Changes in Blood Lipids Consequent to Aerobic Exercise Training Related to Changes in Body Fatness and Aerobic Fitness", Metabolism, 50(7), pp. 841-848, 2001.

38. Erkan, N., Yaşam Boyu Spor, Bağırgan Yayımevi, Ankara, 1998.

39. Williams, P.T., "Health Effects Resultingfrom Exercise Versus Those From Body Fat Loss", Medicine and Science in Sports and Exercise, 33(6), pp. 611-621, 2001. 